\title{
A Population Pharmacokinetic Model Does Not Predict the Optimal Starting Dose of Tacrolimus in Pediatric Renal Transplant Recipients in a Prospective Study: Lessons Learned and Model Improvement
}

\author{
Louise M. Andrews ${ }^{1}$ (D) Brenda C. M. de Winter ${ }^{1} \cdot$ Elisabeth A. M. Cornelissen ${ }^{2} \cdot$ Huib de Jong $^{3} \cdot$ Dennis A. Hesselink $^{4}$. \\ Michiel F. Schreuder ${ }^{2} \cdot$ Roger J. M. Brüggemann ${ }^{5} \cdot$ Teun van Gelder $^{1,4} \cdot$ Karlien Cransberg $^{3}$
}

Published online: 26 October 2019

(c) The Author(s) 2019

\begin{abstract}
Background and Objective Bodyweight-based dosing of tacrolimus is considered standard care. Currently, at first steady state, a third of pediatric kidney transplant recipients has a tacrolimus pre-dose concentration within the target range. We investigated whether adaptation of the starting dose according to a validated dosing algorithm could increase this proportion. Methods This was a multi-center, single-arm, prospective trial with a planned interim analysis after 16 patients, in which the tacrolimus starting dose was based on bodyweight, cytochrome P450 3A5 genotype, and donor status (living vs. deceased donor).

Results At the interim analysis, $31 \%$ of children had a tacrolimus pre-dose concentration within the target range. As the original dosing algorithm was poorly predictive of tacrolimus exposure, the clinical trial was terminated prematurely. Next, the original model was improved by including the data of the children included in this trial, thereby doubling the number of children in the model building cohort. Data were best described with a two-compartment model with inter-individual variability, allometric scaling, and inter-occasion variability on clearance. Cytochrome P450 3A5 genotype, hematocrit, and creatinine influenced the tacrolimus clearance. A new starting dose model was developed in which the cytochrome P450 3A5 genotype was incorporated. Both models were successfully internally and externally validated.

Conclusions The weight-normalized starting dose of tacrolimus should be higher in patients with a lower bodyweight and in those who are cytochrome P450 3A5 expressers.
\end{abstract}

\section{Key Points}

Electronic supplementary material The online version of this article (https://doi.org/10.1007/s40262-019-00831-8) contains supplementary material, which is available to authorized users.

\section{Louise M. Andrews}

1.andrews@erasmusmc.nl

1 Department of Hospital Pharmacy, Erasmus MC, University Medical Center Rotterdam, P.O. Box 2040, 3000 CA Rotterdam, The Netherlands

2 Department of Pediatric Nephrology, Radboudumc Amalia Children's Hospital, Nijmegen, The Netherlands

3 Department of Pediatric Nephrology, Erasmus MC-Sophia Children's Hospital, Rotterdam, The Netherlands

4 Department of Internal Medicine, Erasmus MC, University Medical Center Rotterdam, Rotterdam, The Netherlands

5 Department of Hospital Pharmacy, Radboud University, Nijmegen, The Netherlands
A validated dosing algorithm could poorly predict the individual starting dose of tacrolimus following renal transplantation in cytochrome $\mathrm{P} 450$ 3A5 expressers receiving a kidney from a deceased donor.

The dosing algorithm was improved and the weightnormalized starting dose of tacrolimus should be higher in patients with lower bodyweight and in those who are cytochrome P450 3A5 expressers.

This study demonstrates that even though a model is validated on paper, it is not necessarily effective in clinical practice. Dosing algorithms should first be tested in prospective studies. 


\section{Introduction}

Tacrolimus is the most commonly used immunosuppressant to prevent acute rejection following renal transplantation [1-4]. Because of its huge medical impact, tacrolimus was chosen by scientists as one of the five molecules to take to a remote island [5]. Nonetheless, prolonged use of tacrolimus leads to substantial toxicity, including increased rates of infection, post-transplant diabetes mellitus, nephrotoxicity, neurotoxicity, hypertension, and gastrointestinal disturbances [6-9]. These adverse events contribute to the limited long-term patient and kidney allograft survival and patient non-adherence [10, 11]. Adverse events seem to be related to higher tacrolimus concentrations, whereas rejection rates seem to be related to lower concentrations $[12,13]$. It is thus important to reach the tacrolimus target concentration as soon as possible to limit the risk of rejection and reduce toxicity $[12,14]$.

Tacrolimus is a critical dose drug with a narrow therapeutic index and large intra- and interpatient variability, for which therapeutic drug monitoring (TDM) is routinely performed [13]. Many factors, including age [15, 16], bodyweight [17-19], cytochrome P450 (CYP) 3A genotype [17, 19], drug-drug interactions [20, 21], ethnicity [22, 23], and hematocrit [17, 19, 24, 25] influence the pharmacokinetics of tacrolimus. Contrary to adults, most published pediatric population pharmacokinetic (PK) models have included either bodyweight or age as a significant covariate influencing clearance (CL) $[21,26]$. To reach the target range, children aged younger than 5 years require higher weight-normalized tacrolimus doses than older children [15]. Currently, in clinical practice and at first steady state, only $30 \%$ of patients are within the target range. Two thirds of children have a concentration outside the target range, $63.5 \%$ having subtherapeutic concentrations, and $6.5 \%$ have supratherapeutic concentrations [17]. In daily practice, the starting dose is often based solely on bodyweight, subsequent doses are adjusted using TDM, which limits the time a patient is exposed to concentrations outside the target range, but it can still take up to 3 weeks before target concentrations are reached [17].

The use of a population PK model may help in predicting an individual's tacrolimus exposure and can be applied before the start of therapy. Recently, our group developed a dosing algorithm to predict the right tacrolimus starting dose in pediatric renal transplant recipients [17]. In this model, the starting dose is based on bodyweight, CYP3A5 genotype, and donor status (living vs. deceased). The model was extensively validated, both internally (bootstrap analysis, visual predictive check [VPC] and normalized prediction distribution errors) and externally (VPC) in an independent cohort consisting of 23 pediatric renal transplant recipients.
Here, we report the results of a prospective clinical trial in pediatric renal transplant recipients in which the tacrolimus starting dose was based on this dosing algorithm [17]. The aim of this trial was to determine if basing the starting dose of tacrolimus on the validated dosing algorithm leads to a higher proportion of patients reaching the tacrolimus target pre-dose concentration $\left(C_{0}\right)$ range $(10-15 \mathrm{ng} / \mathrm{mL})$ at day 3 after transplantation. The number of children we planned to include was 28 and an interim analysis was planned after the inclusion of 16 children. The interim analysis demonstrated that the algorithm did not adequately predict the tacrolimus exposure and therefore the trial was stopped. Subsequently, a new and improved dosing algorithm was developed in a cohort in which the total number of included children was doubled compared to the original cohort.

\section{Methods}

\subsection{Clinical Trial}

This was an investigator-initiated, prospective, openlabel, multi-center clinical trial. Pediatric patients (aged 2-18 years) who were scheduled to receive a single-organ, blood group AB0-compatible kidney at the Erasmus MCSophia Children's Hospital in Rotterdam or the Radboudumc-Amalia Children's Hospital in Nijmegen were eligible for participation. Patients who received immunosuppressive drug treatment in the 28 days prior to transplantation (with the exception of glucocorticoids) and/or used drugs known to interact with tacrolimus (Table S1 of the Electronic Supplementary Material [ESM]) were not included in the study.

All procedures performed in studies involving human participants were in accordance with the ethical standards of the institutional research committee (Erasmus MC, Medical Ethical Review Board number 2017-393) and with the 1964 Helsinki Declaration and its later amendments or comparable ethical standards. The study was registered in the Dutch national trial registry (https://www.trialregister.nl/ trial/6694). Written informed consent was obtained from all patients and/or their parents depending on the age of the patient before inclusion in the study. The PK study was also approved by the institutional review board of the Erasmus MC (Medical Ethical Review Board number 2017-092).

\subsubsection{Intervention}

Patients were prescribed a tacrolimus starting dose based on a published dosing algorithm [17]. This original dosing algorithm is shown in Eq. (1): 


$$
\begin{aligned}
& \text { Dose }(\mathrm{mg} / \text { day }) \\
& =209 \mathrm{ng} \mathrm{h} / \mathrm{mL} * 54.9 *\left(\frac{\text { weight }}{70}\right)^{0.75} \\
& \quad *(1.8, \text { if } C Y P 3 A 5 * 1 / * 3 \text { or } C Y P 3 A 5 * 1 / * 1) \\
& \quad *(0.74, \text { if living donor }) / 1000 .
\end{aligned}
$$

The dose was adjusted based on bodyweight, CYP3A5 status, and donor type. The dosing guideline ranged from 0.27 to $1.33 \mathrm{mg} / \mathrm{kg}$ as shown in Table S2 of the ESM. Both twice-daily formulations Prograft ${ }^{\circledR}$ capsules and Modigraf $^{\circledR}$ granules for suspension (Astellas Pharma, Leiden, the Netherlands) were used. All doses were divided into two equal daily doses administered every $12 \mathrm{~h}$. All patients were treated according to the TWIST protocol with basiliximab, tacrolimus, mycophenolic acid, and a 5-day course of glucocorticoids [14]. Patients were followed for 10 days post-transplantation.

\subsubsection{Endpoints}

The primary endpoint was the proportion of patients within the tacrolimus $C_{0}$ target range $(10-15 \mathrm{ng} / \mathrm{mL})$ after five unaltered tacrolimus doses on day 3 (first steady state) after transplantation. Hereafter, the physician could change the tacrolimus dose based on the tacrolimus $C_{0}$ or the clinical status of the patient. Subsequently, $C_{0}$ were drawn frequently according to local hospital protocol. Clinicians were encouraged to use the following formula to calculate the new dose:

New tacrolimus dose

$$
=\left(\frac{\text { desired tacrolimus } C_{0}}{\text { current tacrolimus } C_{0}}\right) * \text { current tacrolimus dose. }
$$

Secondary endpoints included the proportion of patients within the target range on day 7 and 10 following transplantation, and the proportion of patients with markedly subtherapeutic $(<5.0 \mathrm{ng} / \mathrm{mL})$ or supra-therapeutic $(>20 \mathrm{ng} / \mathrm{mL})$ tacrolimus $C_{0}$ on day 3. Clinical endpoints included the incidence of biopsy-proven acute rejection and serious adverse events during follow-up (10 days) and the 30 days after the follow-up period. Delayed graft function was defined as the need for dialysis in the first week after transplantation.

\subsubsection{Laboratory Analysis}

Tacrolimus concentrations were determined using a validated liquid chromatography-tandem mass spectrometry method as described previously [17]. Genotyping for CYP3A4 and CYP3A5 was performed as described previously [17].

\subsubsection{Statistical Analysis}

With standard tacrolimus dosing, the percentage of patients with a tacrolimus $C_{0}$ within the therapeutic target range on day 3 after transplantation is $30 \%$ in our population [17]. With model-based dosing, this was expected to increase to at least $55 \%$. For the sample size of the study, a minimax Simon two-stage design was used [27]. With $\alpha=0.1$ and $\beta=0.10$, the required number of patients was 25 with an interim analysis involving the first 16 included patients. If after the inclusion of 16 patients, four or fewer patients (or $25 \%$ ) were on target, inclusion of further patients would be terminated. The conclusion of the trial would then be that model-based dosing does not result in a sufficiently high proportion of patients with a $C_{0}$ on target. If at least five patients (or $31 \%$ ) had a tacrolimus $C_{0}$ within the target range, inclusion would be extended. The conclusion of the trial would then be that model-based dosing is effective and results in a sufficiently high proportion of patients with an adequate $C_{0}$ to warrant further research in this population. To account for a $10 \%$ dropout, it was estimated that a total of 28 patients had to be included.

For the analysis, an intention-to-treat approach was followed, which included all patients who received at least one dose of the assigned drug. All secondary endpoints are described for the study population, and also for the historic controls. These historic controls are the 46 children previously transplanted in the Erasmus MC [17]. Possible differences between data from both populations were not formally tested.

\subsection{Improved Dosing Algorithm}

The cohort used to build an improved model consisted of a total of 95 children. Of these patients, 45 had been included in the development of the original model [17]. For the remaining patients, additional PK data were retrospectively retrieved from the medical records. The 16 patients included in the clinical trial described above were added. The remaining 34 patients were transplanted in the Erasmus MC $(n=11)$ or in the Radboudumc $(n=23)$ between March 2012 and October 2017. The Ethics Review Board of the Erasmus MC provided a waiver for the Medical Research Involving Human Subjects Act for this study (Medical Ethical Review Board number 2017-092). No extra laboratory analyses were performed.

\subsubsection{Base Model and Covariate Model Development}

Pharmacokinetic analysis was conducted by nonlinear mixed-effects modeling using NONMEM version 7.2 (FOCE + I; ICON Development Solutions, Ellicott City, MD, USA) and PsN version 4.6.0. Pirana software was used 
as an interface between NONMEM, R (version 3.2.2) and Xpose (version 4). Base model and covariate model development was conducted as described previously [17]. The following demographic, clinical, and genetic characteristics were evaluated as potential covariates: weight, height, sex, age, ethnicity, co-medication (glucocorticoids and calcium channel blockers), glucocorticoid dose, CYP3A4 and CYP3A5 genotype, primary kidney disease, number of transplantations, renal replacement therapy prior to transplantation (pre-emptive, peritoneal dialysis, or hemodialysis), donor status (living or deceased), human leukocyte antigen mismatches, time post-transplant, hematocrit, creatinine, estimated glomerular filtration rate (Schwartz formula [28]), aspartate aminotransferase, albumin, C-reactive protein, and total protein.

\subsubsection{Model Evaluation}

The final model was internally validated with a VPC with 500 simulated datasets and a normalized prediction distribution error analysis with 1000 simulations as described previously [17]. The VPC was stratified for the included covariates. To evaluate the effect of the significant covariates, simulations were performed using the final model with varying parameters for the covariate. All other parameters were fixed to the mean.

\subsubsection{Starting Dose Algorithm}

To be able to predict the required tacrolimus starting dose, the final model was used to develop a starting dose algorithm. Each significant covariate in the final model was evaluated if it was clinically relevant, feasible to use, and if it significantly influenced the starting dose of tacrolimus. The starting dose model was validated using the techniques mentioned above.

\section{Results}

\subsection{Prospective Trial}

The study was conducted between 19 November 2017 (first patient, first visit) and 19 February 2019 (last patient, last visit). A total of 19 patients was screened for participation in the trial of which 17 were eligible (Fig. 1). Sixteen patients gave written informed consent and were subsequently included ( $n=13$ in the Erasmus MC and $n=3$ in Radboudumc). Patient characteristics are shown in Table 1. Of these patients, 15 completed the 10-day follow-up. One patient was accidently administered tacrolimus extended release

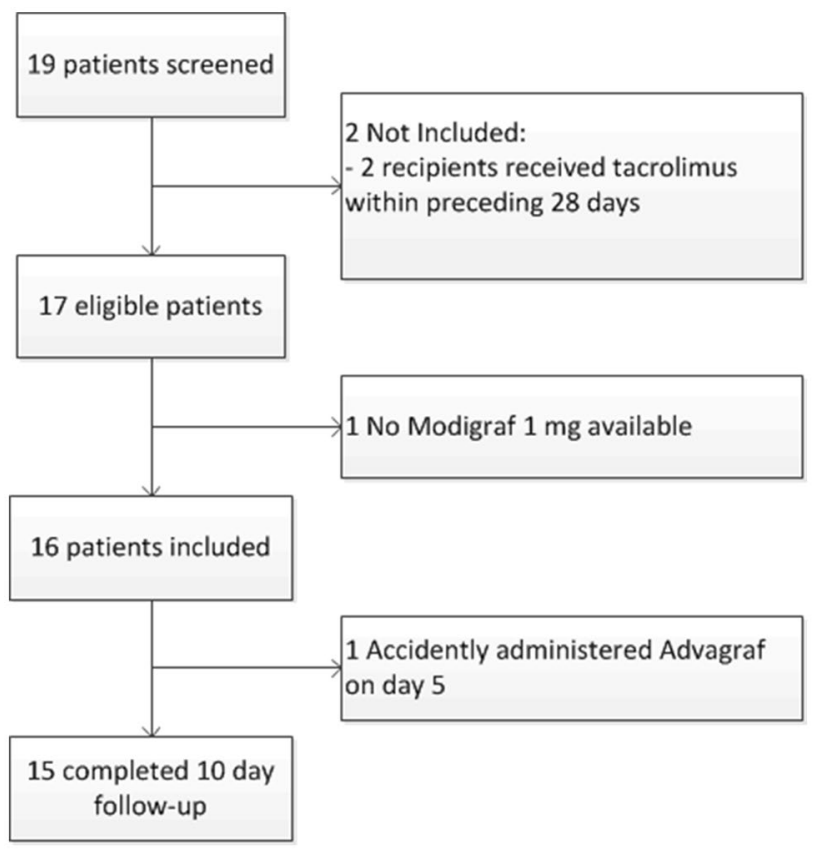

Fig. 1 Trial flowchart. All patients who underwent a kidney transplantation and received at least one dose of tacrolimus according to the dosing algorithm were included in the intention-to-treat population

(Advagraf; Astellas Pharma) on day 5 and discontinued the study.

The CYP3A5 allele frequencies are shown in Table 1. The observed CYP3A5 genotype distribution was in accordance with the Hardy-Weinberg equilibrium $\left(\chi^{2}=1.34 ; p=0.25\right)$.

\subsubsection{Endpoints and Discontinuation of the Study}

At the pre-planned interim analysis (after the inclusion of $n=16$ children), five children (31\%) had a tacrolimus $C_{0}$ within the target range $(10-15 \mathrm{ng} / \mathrm{mL}), 31 \%$ had a supratherapeutic $C_{0}$, and $38 \%$ a subtherapeutic $C_{0}$ on day 3 after transplantation (Table 2). This number was set before the study as a minimum to continue the study.

The algorithm predicted really high doses (i.e., $0.80 \mathrm{mg} /$ $\mathrm{kg}$ /day) in patients who were CYP3A5 expressers and received a kidney from a deceased donor $(n=3)$. Considering these high doses, in these patients, a tacrolimus $C_{0}$ was measured already on day 1 or 2 following transplantation. These $C_{0}$ were too high, and the tacrolimus dose was subsequently reduced before day 3 (the primary endpoint). Two children $(12.5 \%)$ had a markedly sub-therapeutic tacrolimus $C_{0}(<5 \mathrm{ng} / \mathrm{mL})$ on day 3 , and three children (19\%) had a markedly supra-therapeutic ( $>20 \mathrm{ng} / \mathrm{mL}$ ) tacrolimus $C_{0}$ on day 3 after transplantation. After TDM was performed, three children (20\%) had a tacrolimus $C_{0}$ within the target range on day 7 , compared with five children $(36 \%)$ on day 10 . The 
Table 1 Patient characteristics

\begin{tabular}{|c|c|}
\hline & $\begin{array}{l}\text { Clinical trial } \\
\text { patients }(n=16)\end{array}$ \\
\hline \multicolumn{2}{|l|}{ Sex, $n(\%)$} \\
\hline Male & $12(75.0)$ \\
\hline Age (years) ${ }^{\mathrm{a}}$ & $15.0(4.6-16.8)$ \\
\hline \multicolumn{2}{|l|}{ Ethnicity, $n(\%)$} \\
\hline Caucasian & $11(68.8)$ \\
\hline Asian & $0(0)$ \\
\hline African descent & $2(12.5)$ \\
\hline Other & $3(18.9)$ \\
\hline Bodyweight $(\mathrm{kg})^{\mathrm{a}}$ & $50.3(15.7-80.4)$ \\
\hline Height $(\mathrm{cm})^{\mathrm{a}}$ & $161(101-179)$ \\
\hline \multicolumn{2}{|l|}{ Genotype, $n(\%)$} \\
\hline \multicolumn{2}{|l|}{ CYP3A5 } \\
\hline$* 1 / * 1$ & $1(6.3)$ \\
\hline$* 1 / * 3$ & $3(18.9)$ \\
\hline$* 3 / * 3$ & $12(75.0)$ \\
\hline \multicolumn{2}{|l|}{ CYP3A4 } \\
\hline$* 1 / * 1$ & $13(81.3)$ \\
\hline$* 1 / * 1 \mathrm{G}$ & $2(12.5)$ \\
\hline$* 1 \mathrm{G} / * 1 \mathrm{G}$ & $1(6.3)$ \\
\hline \multicolumn{2}{|l|}{ Primary diagnosis, $n(\%)$} \\
\hline CAKUT & $7(43.8)$ \\
\hline Glomerular kidney disease & $1(6.3)$ \\
\hline Cystic kidney disease/nephronophthisis & $3(18.9)$ \\
\hline Other/unknown & $5(31.3)$ \\
\hline \multicolumn{2}{|l|}{ RRT prior to kidney transplantation, $n(\%)$} \\
\hline Hemodialysis & $5(31.3)$ \\
\hline Peritoneal dialysis & $3(18.9)$ \\
\hline Pre-emptive & $8(50.0)$ \\
\hline \multicolumn{2}{|l|}{ Donor type, $n(\%)$} \\
\hline Living & $11(68.8)$ \\
\hline Deceased & $5(31.3)$ \\
\hline \multicolumn{2}{|l|}{ Number of HLA mismatches, $n(\%)$} \\
\hline 0 & $2(12.5)$ \\
\hline 1 & $1(6.3)$ \\
\hline 2 & $3(18.9)$ \\
\hline 3 & $7(43.8)$ \\
\hline 4 & $3(18.9)$ \\
\hline
\end{tabular}

$C A K U T$ congenital anomalies of the kidney and the urinary tract, CYP cytochrome P450, HLA human leukocyte antigen, RRT renal replacement therapy

${ }^{\text {a }}$ Presented as median and range for continuous variables

individual tacrolimus $C_{0}$ during the follow-up is shown in Fig. 2. The tacrolimus $C_{0}$ on days 3,7 , and 10 are shown in Fig. 3.

Although the a priori criteria for a successful study were met ( $31 \%$ of children on target at day 3 after transplantation), we decided to discontinue the study prematurely and to improve the model using new data. The reasons for this were two fold. First, at the interim analysis, it was discovered that the model performed poorly in CYP3A5 expressers receiving a kidney from a deceased donor, which constituted $25 \%$ of all children included in this prospective study. Second, there was considerable concern among clinicians regarding overdosing in patients who were CYP3A5 expressers and received a kidney from a deceased donor.

\subsubsection{Safety}

Overall, patient and graft survival was $100 \%$. The incidence of biopsy-proven acute rejection during the follow-up was $6.3 \%(n=1)$. One child had antibody-mediated rejection on day 8 and was treated with methylprednisolone and immunoglobulins. At the time of biopsy, tacrolimus $C_{0}$ was $3.9 \mathrm{ng} /$ $\mathrm{mL}$. Just after the follow-up finished (day 13), one patient was diagnosed with acute cellular rejection Banff grade $2 \mathrm{~A}$ and was treated with methylprednisolone. At the time of biopsy, tacrolimus $C_{0}$ was $18.7 \mathrm{ng} / \mathrm{mL}$. Both children fully recovered. The incidence of delayed graft function was $6.25 \%(n=1)$. Tacrolimus $C_{0}$ on day 3 of this patient was $21.4 \mathrm{ng} / \mathrm{mL}$. During the 30 days after the follow-up period had finished, one patient reported a serious adverse event. This child developed post-transplant diabetes mellitus, and was switched to ciclosporin-based immunosuppressive therapy, and fully recovered. At the time of diagnosis, tacrolimus $C_{0}$ was relatively high $(18 \mathrm{ng} / \mathrm{mL})$.

\subsection{Improved Dosing Algorithm}

As the trial was ended prematurely, a new dosing algorithm was developed in an extended cohort. The model building cohort was expanded to a total of 95 children. Patient characteristics are presented in Table 3. From these patients, a total of 1138 blood samples were collected and analyzed for tacrolimus concentrations (range 1.8-109.0 ng/mL). No samples were below the lower limit of quantification. One sample was above the upper limit of quantification and was discarded. A fifth of the samples was drawn within the first week following transplantation. For 90 patients, at least one PK profile at a median of 12.2 days (range 4.2-42.0 days) post-transplantation was available. The CYP3A4 and CYP3A5 allele frequencies are depicted in Table 3. There was no deviation from the Hardy-Weinberg equilibrium.

\subsubsection{Pharmacokinetic Model Development}

The data were best described with a two-compartment model. Including inter-individual variability on clearance $(\mathrm{CL} / F)$, volume of distribution of the central compartment, volume of distribution of the peripheral compartment, and the absorption rate constant significantly improved the 
Table 2 Clinical trial results

\begin{tabular}{|c|c|c|c|c|c|c|c|c|}
\hline \multirow{2}{*}{$\begin{array}{l}\text { Body- } \\
\text { weight } \\
(\mathrm{kg})\end{array}$} & \multirow[t]{2}{*}{ CYP3A5 } & \multirow[t]{2}{*}{ Donor } & \multicolumn{2}{|l|}{ Day 3} & \multicolumn{2}{|l|}{ Day 7} & \multicolumn{2}{|l|}{ Day 10} \\
\hline & & & $\begin{array}{l}\text { Tac dose } \\
\text { (mg/kg/day) }\end{array}$ & Tac $C_{0}$ & $\begin{array}{l}\text { Tac dose } \\
\text { (mg/kg/day) }\end{array}$ & $\operatorname{Tac} C_{0}$ & $\begin{array}{l}\text { Tac dose } \\
(\mathrm{mg} / \mathrm{kg} / \text { day })\end{array}$ & Tac $C_{0}$ \\
\hline 65 & $* 3 / * 3$ & LD & 0.31 & 11.3 & 0.31 & 17.8 & 0.25 & 14.9 \\
\hline 80.4 & $* 1 / * 3$ & DD & 0.80 & $21.4^{\mathrm{a}}$ & 0.22 & 35.0 & 0.22 & 15.7 \\
\hline 48.2 & $* 1 / * 1$ & $\mathrm{DD}$ & 0.79 & $17.9^{\mathrm{a}}$ & 0.29 & 15.3 & 0.37 & 4.6 \\
\hline 51.3 & $* 3 / * 3$ & DD & 0.39 & 9.8 & 0.39 & 16.9 & 0.31 & 13.3 \\
\hline 15.7 & $* 3 / * 3$ & LD & 0.38 & 7.4 & 0.51 & 12.0 & 0.51 & 9.7 \\
\hline 70.1 & $* 3 / * 3$ & LD & 0.29 & 4.2 & 0.43 & 16.0 & 0.37 & 20.8 \\
\hline 62.2 & $* 1 / * 3$ & DD & 0.64 & $11^{\mathrm{b}}$ & 0.48 & 18.6 & 0.42 & 17.7 \\
\hline 57.7 & $* 3 / * 3$ & LD & 0.29 & 11.9 & 0.33 & 22.2 & 0.26 & 13.7 \\
\hline 29.9 & $* 1 / * 3$ & LD & 0.54 & 4.1 & 0.67 & 8.5 & 0.67 & 10.6 \\
\hline 26.3 & $* 3 / * 3$ & DD & 0.46 & 7.2 & 0.61 & 14.6 & 0.53 & 14.4 \\
\hline 39.3 & $* 3 / * 3$ & LD & 0.31 & 5.3 & 0.31 & 23.5 & 0.15 & 18.1 \\
\hline 49.3 & $* 3 / * 3$ & LD & 0.28 & 24 & 0.20 & 17.4 & 0.12 & 16.7 \\
\hline 41.5 & $* 3 / * 3$ & LD & 0.31 & 10.9 & $\mathrm{NA}^{\mathrm{c}}$ & NA & NA & NA \\
\hline 63.6 & $* 3 / * 3$ & LD & 0.31 & 10.3 & 0.31 & 11.7 & 0.19 & 8.0 \\
\hline 59.3 & $* 3 / * 3$ & LD & 0.30 & 10.8 & 0.24 & 21.3 & 0.17 & 22.3 \\
\hline 19.3 & $* 3 / * 3$ & LD & 0.36 & 21.3 & 0.26 & 21.3 & 0.21 & NA \\
\hline
\end{tabular}

$C_{0}$ pre-dose concentration, $C Y P$ cytochrome $\mathrm{P} 450, D D$ deceased donor, $L D$ living donor, $N A$ not available, Tac tacrolimus

${ }^{a}$ Patients had a toxic tacrolimus $C_{0}$ on days 1-2 following transplantation. The tacrolimus dose was subsequently reduced

${ }^{b}$ Patient had a concentration of $11 \mathrm{ng} / \mathrm{mL}$ after just one dose of tacrolimus. The tacrolimus dose was subsequently reduced

${ }^{c}$ Patient discontinued the study after accidental administration of Advagraf

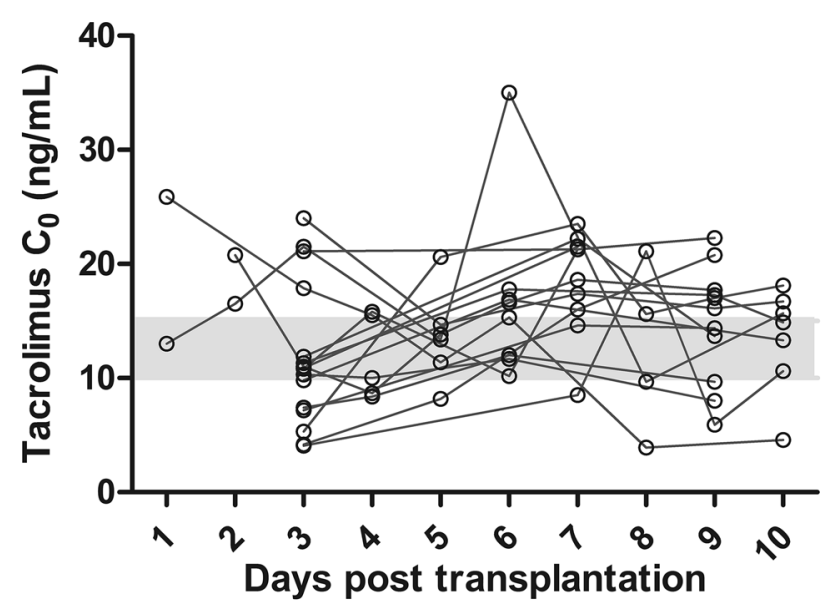

Fig. 2 Individual tacrolimus pre-dose concentrations $\left(C_{0}\right)$ in the 10 days following kidney transplantation

model fit. Allometric scaling with an estimated exponent on CL/ $F$ and fixed exponent on volume of distribution of the central compartment (1) and volume of distribution of the peripheral compartment (1) significantly improved the model $(p<0.001)$. The objective function value decreased

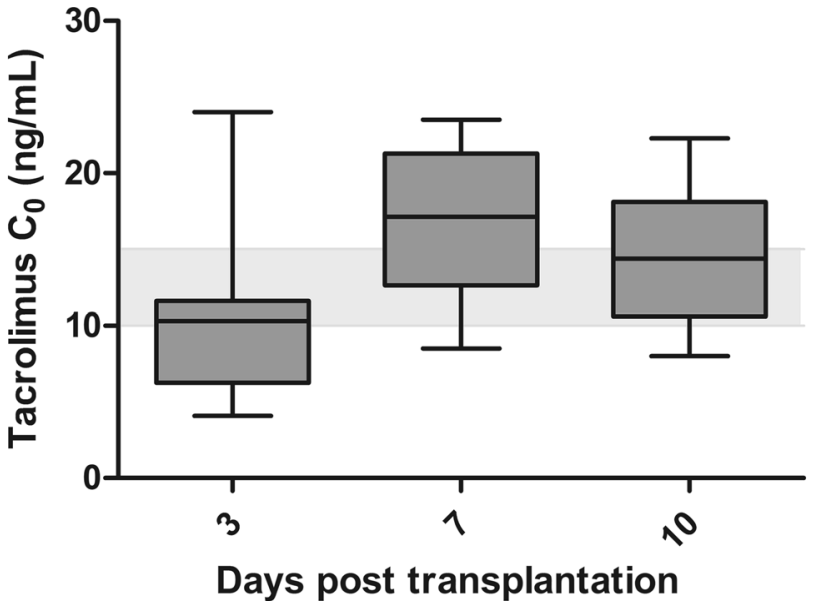

Fig. 3 Boxplot depicting the tacrolimus pre-dose concentrations $\left(C_{0}\right)$ on days 3,7 , and 10 following transplantation. In this figure, the three patients who had a dose reduction before day 3 are excluded

further after adding inter-occasion variability on CL/F. The residual error was described with a combined additive and proportional error model for the immunoassay measured concentrations, and a separate additive and proportional error model for the liquid chromatography-tandem 
Table 3 Patient characteristics improved pharmacokinetic model

Model building cohort $(n=95)$

\begin{tabular}{|c|c|}
\hline \multicolumn{2}{|l|}{ Recipient sex, $n(\%)$} \\
\hline Male & $58(61)$ \\
\hline Age of recipient (years) & $11.4(1.6-17.9)$ \\
\hline \multicolumn{2}{|l|}{ Ethnicity, $n(\%)$} \\
\hline Caucasian & $71(74)$ \\
\hline Asian & $2(2)$ \\
\hline African descent & $9(9)$ \\
\hline Other & $13(14)$ \\
\hline Bodyweight $(\mathrm{kg})^{\mathrm{a}}$ & $32.0(10.4-87.5)$ \\
\hline Height $(\mathrm{cm})^{\mathrm{a}}$ & $138(73-188)$ \\
\hline \multicolumn{2}{|l|}{ Laboratory measurements } \\
\hline Hematocrit (L/L) & $0.29(0.16-0.52)$ \\
\hline Creatinine $(\mu \mathrm{mol} / \mathrm{L})$ & $84(12-1454)$ \\
\hline eGFR (mL/min) [28] & $63(2.9-274)$ \\
\hline ASAT (U/L) & $29(7-217)$ \\
\hline Albumin (g/L) & $34(11-52)$ \\
\hline $\mathrm{CRP}(\mathrm{mg} / \mathrm{L})$ & $6.4(0.3-268)$ \\
\hline Total protein $(\mathrm{g} / \mathrm{L})$ & $61(34-80)$ \\
\hline \multicolumn{2}{|l|}{$C Y P 3 A 4, n(\%)$} \\
\hline$* 1 / * 1$ & $34(36)$ \\
\hline$* 1 / * 1 \mathrm{G}$ & $8(8)$ \\
\hline$* 1 \mathrm{G} / * 1 \mathrm{G}$ & $3(3)$ \\
\hline$* 22$ & $2(2)$ \\
\hline Unknown & $48(51)$ \\
\hline \multicolumn{2}{|l|}{$C Y P 3 A 5, n(\%)$} \\
\hline$* 1 / * 1$ & $3(3)$ \\
\hline$* 1 / * 3$ & $11(12)$ \\
\hline$* 3 / * 3$ & $52(55)$ \\
\hline$* 3 / * 7$ & $2(2)$ \\
\hline Unknown & $27(28)$ \\
\hline \multicolumn{2}{|l|}{ Primary diagnosis, $n(\%)$} \\
\hline CAKUT & $46(48)$ \\
\hline Glomerular kidney disease & $22(23)$ \\
\hline Cystic kidney disease/nephronophthisis & $12(13)$ \\
\hline Other/unknown & $15(16)$ \\
\hline \multicolumn{2}{|l|}{ Number of kidney transplantations, $n(\%)$} \\
\hline First & $90(95)$ \\
\hline Second & $5(5)$ \\
\hline \multicolumn{2}{|l|}{ RRT prior to kidney transplantation, $n(\%)$} \\
\hline Hemodialysis & $28(29)$ \\
\hline Peritoneal dialysis & $23(24)$ \\
\hline Pre-emptive & $44(46)$ \\
\hline \multicolumn{2}{|l|}{ Donor type, $n(\%)$} \\
\hline Living & $74(78)$ \\
\hline Deceased & $21(22)$ \\
\hline \multicolumn{2}{|l|}{ Route of administration, $n(\%)$} \\
\hline Suspension & $24(25)$ \\
\hline Capsule & $89(94)$ \\
\hline
\end{tabular}

Table 3 (continued)

\begin{tabular}{ll}
\hline & $\begin{array}{l}\text { Model building } \\
\text { cohort }(n=95)\end{array}$ \\
\hline Co-medication, $n(\%)$ & \\
Calcium channel blockers & $51(54)$ \\
Amlodipine & $23(24)$ \\
Nifedipine & \\
Antibiotics & $1(1)$ \\
Erythromycin & \\
Antimycotics & $2(2)$ \\
Fluconazole & $1(1)$ \\
Voriconazole & \\
Distribution of tacrolimus samples & 1338 \\
Total samples & $286(21)$ \\
$0-7$ days post-transplantation & $515(38)$ \\
8-14 days post-transplantation & $218(16)$ \\
15-21 days post-transplantation & $319(24)$ \\
22-42 days post-transplantation & \\
Tacrolimus analysis & $64(4.8)$ \\
Immunoassay & $1274(95.2)$ \\
LC-MS/MS &
\end{tabular}

$A S A T$ aspartate aminotransferase, $C_{0}$ pre-dose concentration, $C A K U T$ congenital anomalies of the kidney and the urinary tract, $C Y P$ cytochrome $\mathrm{P} 450, e G F R$ estimated glomerular filtration rate, $L C-M S /$ $M S$ liquid chromatography-tandem mass spectrometry, $R R T$ renal replacement therapy

${ }^{\text {a }}$ Presented as median and range for continuous variables

mass spectrometry measured concentrations. Parameter estimates of the base model, final model, and starting dose model are presented in Table 4.

After graphical analysis, the univariate analysis resulted in five significant covariates correlated with CL/F: hematocrit, CYP3A5, African descent, serum creatinine during followup, and estimated glomerular filtration rate. After forward inclusion-backward elimination (stepwise covariate modeling method [29]), CYP3A5, hematocrit, and serum creatinine remained in the final model. The final model for estimation of tacrolimus $\mathrm{CL} / F$ in the first 6 weeks after transplantation is shown in Eq. (2):

$$
\begin{aligned}
\mathrm{CL} / F= & 36.6 *\left(\frac{\text { weight }}{70}\right)^{0.62} *[(1.0, \text { if } C Y P 3 A 5 * 3 / * 3) \\
& \text { or }(1.4, \text { if } C Y P 3 A 5 * 1 / * 3 \text { or } C Y P 3 A 5 * 1 / * 1)] \\
& *\left(\frac{\text { Hematocrit }}{0.29}\right)^{-0.6} *\left(\frac{\text { Creatinine }}{84}\right)^{-0.1} .
\end{aligned}
$$

The final model was used to develop a model to predict the starting dose of tacrolimus. As time after transplantation was not a significant covariate, the same database was used to create the starting dose model. The last measured hematocrit and 
Table 4 Parameter estimates of the base model, final model, and bootstrap analysis

\begin{tabular}{|c|c|c|c|}
\hline Parameter & $\begin{array}{l}\text { Base model (RSE \%) } \\
\text { [shrinkage] }\end{array}$ & $\begin{array}{l}\text { Final model (RSE \%) } \\
\text { [shrinkage] }\end{array}$ & $\begin{array}{l}\text { Starting dose model } \\
\text { (RSE \%) [shrinkage] }\end{array}$ \\
\hline$t_{\text {lag }}(\mathrm{h}) \mathrm{FIX}$ & 0.41 & 0.41 & 0.41 \\
\hline$k_{\mathrm{a}}(\mathrm{L} / \mathrm{h})$ & $2.1(19)$ & $1.7(11)$ & $1.85(24)$ \\
\hline $\mathrm{CL} / F(\mathrm{~L} / \mathrm{h} / 70 \mathrm{~kg})$ & $37.0(6)$ & $36.6(12)$ & $34.5(6)$ \\
\hline$V_{1} / F(\mathrm{~L} / 70 \mathrm{~kg})$ & $560(12)$ & $496(22)$ & $540(12)$ \\
\hline$Q / F(\mathrm{~L} / \mathrm{h})$ & $27.4(16)$ & 31.7 (19) & $28.5(12)$ \\
\hline$V_{2} / F(\mathrm{~L} / 70 \mathrm{~kg})$ & $1600(13)$ & $1270(13)$ & $1660(17)$ \\
\hline Allometric scaling on CL & $0.57(10)$ & $0.62(20)$ & $0.56(9)$ \\
\hline \multicolumn{4}{|l|}{ Covariate effect on CL } \\
\hline CYP $3 \mathrm{~A} 5 * 1 / * 1$ or $* 1 / * 3$ & - & 1.4 & 1.5 \\
\hline Hematocrit (L/L) & - & -0.60 & - \\
\hline Creatinine $(\mu \mathrm{mol} / \mathrm{L})$ & - & -0.1 & - \\
\hline \multicolumn{4}{|l|}{ IIV (\%) } \\
\hline $\mathrm{CL} / F$ & $47.2(8)[4]$ & $42.1(10)[5]$ & $42.3(11)[3]$ \\
\hline$V_{1} / F$ & $89.0(12)[11]$ & $99.6(12)[10]$ & $93.0(12)[8]$ \\
\hline$V_{2} / \mathrm{F}$ & $92.1(15)[20]$ & $85.2(15)[22]$ & 89.3 (15) [19] \\
\hline$k_{\mathrm{a}}$ & $172(10)[23]$ & $183(11)[20]$ & $178(10)[22]$ \\
\hline \multicolumn{4}{|l|}{ IOV $(\%)$} \\
\hline $\mathrm{CL} / F$ & 20.7 (9) & $20.1(20)$ & $20.1(10)$ \\
\hline \multicolumn{4}{|l|}{ Residual variability } \\
\hline \multicolumn{4}{|l|}{ Additional } \\
\hline Immunoassay & 0.77 & 1.27 & 1.01 \\
\hline LC-MS/MS & 0.94 & 0.87 & 0.96 \\
\hline \multicolumn{4}{|l|}{ Proportional } \\
\hline Immunoassay & 0.12 & 0.11 & 0.12 \\
\hline LC-MS/MS & 0.23 & 0.23 & 0.24 \\
\hline
\end{tabular}

$C L$ clearance, $C Y P$ cytochrome $\mathrm{P} 450, F$ bioavailability, IIV inter-individual variability, $I O V$ inter-occasion variability, $k_{a}$ absorption rate constant, $L C-M S / M S$ liquid chromatography-tandem mass spectrometry, $Q$ inter-compartmental clearance, $R S E$ residual standard error, $t_{\text {lag }}$ lag time, $V_{I}$ volume of distribution of the central compartment, $V_{2}$ volume of distribution of the peripheral compartment serum creatinine before transplantation did not significantly influence the $\mathrm{CL} / F$, and were not included in the starting dose model. Equation 3 describes the starting dose model:

$$
\begin{aligned}
\mathrm{CL} / F= & 34.5 *\left(\frac{\text { weight }}{70}\right)^{0.56} *[(1.0, \text { if } C Y P 3 A 5 * 3 / * 3) \\
& \text { or }(1.46, \text { if } C Y P 3 A 5 * 1 / * 3 \text { or } C Y P 3 A 5 * 1 / * 1)] .
\end{aligned}
$$

To calculate the required dose, the PK formula of dose $=\mathrm{CL} / F *$ AUC can be used. A $C_{0}$ of $10 \mathrm{ng} / \mathrm{mL}$ corresponded with an $\mathrm{AUC}_{0-12 \mathrm{~h}}$ of $185 \mathrm{ng} \mathrm{h} / \mathrm{mL}, 12.5 \mathrm{ng} / \mathrm{mL}$ with $220 \mathrm{ng} \mathrm{h} / \mathrm{mL}$, and $15 \mathrm{ng} / \mathrm{mL}$ with $254 \mathrm{ng} \mathrm{h} / \mathrm{mL}$. For a target of $12.5 \mathrm{ng} / \mathrm{mL}$, this leads to Eq. (4) for the starting daily dose based on a twice-daily prescription (improved dosing algorithm):

$$
\begin{aligned}
\operatorname{Dose}(\mathrm{mg} / \text { day })= & 220 * 34.5 *\left(\frac{\text { weight }}{70}\right)^{0.56} \\
& *[(1.0, \text { if } C Y P 3 A 5 * 3 / * 3) \\
& \operatorname{or}(1.46, \text { if } C Y P 3 A 5 * 1 / * 3 \\
& \text { or } C Y P 3 A 5 * 1 / * 1)] / 1000 .
\end{aligned}
$$

An example of calculated doses according to Eq. (4) is given in Table S3 of the ESM.

\subsubsection{Evaluation of the Final Model and Starting Dose Model}

All estimates were within the limits, except for shrinkage on $V_{3}$, which was $22 \%$. Goodness-of-fit plots of the final model and starting dose model showed both the individual and population predictions were evenly distributed around the line of unity (Fig. 4). The median and variability of the $C_{0}$ fell within the corresponding simulations as shown in the prediction-corrected VPCs (Fig. S1 of the ESM). Normalized prediction distribution errors were acceptably deviated from a normal distribution and values were mostly between -2 and 2 , showing the adequate predictive ability of the model. A shark plot showed $68 \%$ of patients had a decrease in objective function value with the final model compared with the base model. 

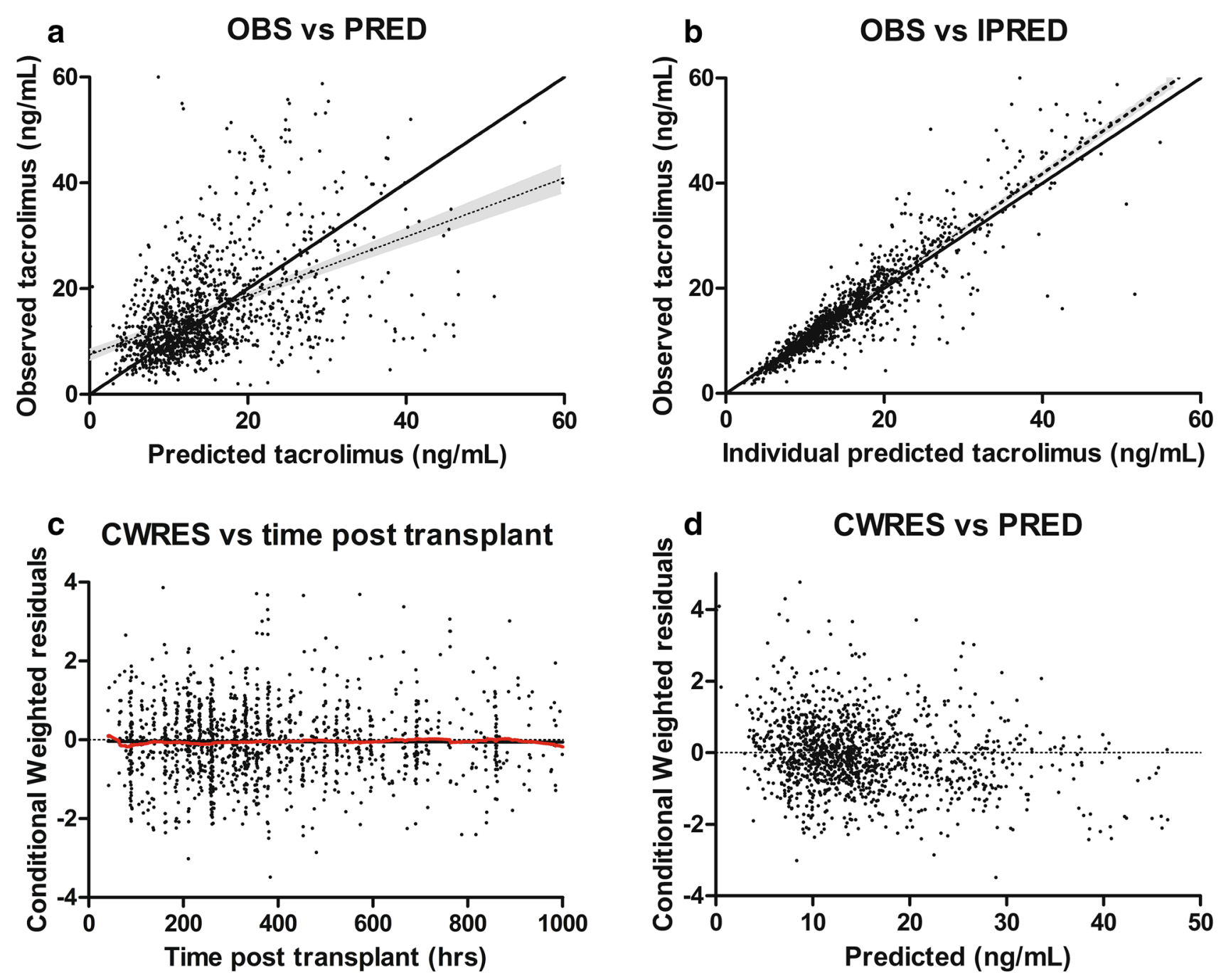

Fig. 4 Goodness-of-fit plots of the final model. a Observed concentrations (OBS) DV plotted against predicted concentration (PRED). b DV plotted against individual predicted concentration (IPRED). $\mathbf{c}$ The correlation of conditional weighted residuals (CWRES) with the time

after the tacrolimus dose. $\mathbf{d}$ The correlation of CWRES with PRED. The line represents the line of identity. $D V$ dependent variable (measured concentration)

\subsubsection{Simulations}

\section{Discussion}

Based on the final model, CYP3A5 expressers had a 1.4-fold higher $\mathrm{CL} / F$ than the CYP3A5 non-expressers. A decrease in hematocrit levels from 0.35 to $0.25 \mathrm{~L} / \mathrm{L}$ corresponded with an $18 \%$ higher tacrolimus CL/F. A decrease in serum creatinine concentration from 500 to $50 \mu \mathrm{mol} / \mathrm{L}$ was associated with a $21 \%$ increase in CL/F. The effect of CYP3A5, bodyweight, serum creatinine, and hematocrit are shown in Fig. S2 of the ESM. In total, these covariates explained 39\% of the variability in $\mathrm{CL} / F$.

In this prospective trial, $31 \%$ (five out of 16) of the children had a tacrolimus $C_{0}$ within the target range on day 3 following transplantation when prescribed a tacrolimus starting dose based on the original dosing algorithm. Two children (12.5\%) had a markedly subtherapeutic tacrolimus $C_{0}(<5 \mathrm{ng} / \mathrm{mL})$ on day 3 , and $3(19 \%)$ had a markedly supratherapeutic $(>20 \mathrm{ng} / \mathrm{mL})$ tacrolimus $C_{0}$. The original algorithm performed worse than anticipated and was comparable to the weight-based prescription, and therefore the trial was ended prematurely. 
Contrary to what we expected, only $31 \%$ of patients had a tacrolimus $C_{0}$ within the target range. When the tacrolimus starting dose is only based on bodyweight in children, $30 \%$ is on target on day 3 [17]. For the model to be a meaningful addition to standard bodyweight-based dosing, our estimate was that at least $55 \%$ would have to be on target. Based on our results, it seems that basing the starting dose on the original dosing algorithm does not increase the percentage of patients on target and does not reduce the number of extreme high and low tacrolimus $C_{0}$ compared with standard bodyweight-based dosing.

There is compelling evidence that CYP3A5 expressers require a 1.5 - to 2 -fold higher tacrolimus dose than nonexpressers [15, 17-19, 30-36]. A randomized clinical trial of age- and genotype-guided tacrolimus dosing in children concluded that CYP3A5 genotype-guided dosing stratified by age resulted in earlier attainment of therapeutic tacrolimus concentrations and fewer out-of-range concentrations [37]. Clinical outcomes were not studied. Two large clinical trials in adults studied whether basing the tacrolimus dose on CYP3A5 would lead to more patients within the target $C_{0}$ range. Both studies concluded that optimization of the initial tacrolimus dose using CYP3A5 genetic testing does not improve clinical outcomes when TDM is performed [38, 39]. As the variability in CL is not solely based on CYP3A5, basing the starting dose on a dosing algorithm including clinical, genetic, and demographic factors seemed the sensible next step.

On day 3 following transplantation, five patients were on target. As they were all CYP3A5 non-expressers who received a kidney from a living donor, they were all prescribed a dosage of approximately $0.3 \mathrm{mg} / \mathrm{kg} / \mathrm{day}$. This is the same dose as the standard bodyweight-based dose according to the package leaflet [40]. These children would have been on target regardless if they participated in this trial.

Six children had a subtherapeutic tacrolimus $C_{0}$ on day 3. All of these children received a dose between 0.29 and $0.54 \mathrm{mg} / \mathrm{kg} / \mathrm{day}$, which is equal to or higher than the standard bodyweight-based dose of $0.3 \mathrm{mg} / \mathrm{kg}$. This suggests that if they had not participated in the trial and received a standard bodyweight-based dose, these children would also all have had a subtherapeutic tacrolimus exposure. Of these children, one was a CYP3A5 expresser and one received a kidney from a deceased donor. The doses were calculated correctly. It seems other factors not included in the original algorithm increased tacrolimus CL in these patients.

In three patients, the tacrolimus dose was reduced on days 1-2 following transplantation owing to a high tacrolimus $C_{0}$. If these doses had not been reduced, these patients would have likely had toxic tacrolimus $C_{0}$ on day 3 . These patients all received a kidney from a deceased donor and were CYP3A5 expressers. It seems that the original dosing algorithm overestimates the CL of tacrolimus in this group, and therefore overestimates the required tacrolimus dose. To our knowledge, no other publication has found a relationship between donor type and tacrolimus CL. As tacrolimus undergoes hepatic metabolism, a higher tacrolimus CL in kidneys from a deceased donor seems highly unlikely. All patients received the same immunosuppressive protocol, no patients experienced delayed graft function. Dialysis prior to transplantation and the number of human leukocyte antigen mismatches were not significantly associated with the tacrolimus CL. The higher tacrolimus CL in kidneys from a deceased donor is probably caused by other unknown parameters that could not be tested as covariates and therefore cannot be corrected for. The cohort in which the model was developed [17] consisted of 46 children of whom only two were CYP3A5 expressers and received a kidney from a deceased donor. It seems that there was insufficient power in the cohort in which the model was developed to determine adequate tacrolimus exposure predictions in this specific subgroup.

After improving the original dosing algorithm, CYP3A5 expressers required a 1.4-fold higher tacrolimus dose than CYP3A5 non-expressers in the improved dosing algorithm. This is in line with previous research mentioned above. As approximately $70-80 \%$ of tacrolimus is distributed in erythrocytes, low hematocrit reduces the whole-blood concentration of tacrolimus [41]. In this study, we concluded that patients with a higher hematocrit had a lower CL/F. Previous research substantiates these findings [17, 19, 31, 35, 36, 42-45]. Hematocrit did not influence the starting dose and was therefore not included in the dosing algorithm. Patients with higher serum creatinine levels had a decreased $\mathrm{CL} / F$. Tacrolimus undergoes hepatic elimination and almost no renal elimination, thus the explanation for this observation remains unclear. Some studies have reported a correlation between creatinine and tacrolimus CL [31, 46, 47], whereas others found no such effect [48-50]. Four decades previously, Sheiner et al. concluded that forecasting a concentration based on covariates does not improve accuracy and precision as much as one previous concentration [51]. However, when predicting the optimal starting dose, no previous concentrations are available. In this first exploratory study, we chose to focus on the starting dose with a historic cohort. For a new study, it will be interesting to adjust the subsequent doses using the dosing algorithm in combination with the previous concentration rather than just TDM.

The main difference between the improved PK model and the original model used to determine the tacrolimus starting dose in this trial is that donor status was no longer a significant covariate on CL. It remains unclear why a recipient of a kidney from a deceased donor would have a higher tacrolimus CL. The other difference between the two models is that allometric scaling was coded with an estimated exponent on CL and CYP3A5 expressers should receive a 1.46-fold 
higher dose in the improved algorithm compared with 1.82 in the original. Simulations of the improved model showed better description of the data compared with the previously published model, as shown in the VPC (Fig. S3 of the ESM). It will be interesting to see if the improved model is able to adequately predict the tacrolimus exposure when used in clinical practice. We are currently planning a new prospective clinical trial using this new and improved algorithm.

The main strength of this study is that this is the first attempt at predicting the optimal starting dose of tacrolimus in children in clinical practice with a dosing algorithm. Many PK models that have been published in the literature were developed retrospectively but were not tested in prospective studies. This study has demonstrated that even though on paper the algorithm was validated extensively and performed well, in clinical practice, it was simply inadequate. As the old proverb says, the proof of the pudding is in the eating. A second strong point is that because of the chosen methodology, a limited sample size was sufficient to answer the research question. The final strength of this study is that an improved starting dose model was developed and designed for clinicians, making it easy to use the dosing algorithm in clinical practice.

The main limitation of this study is that in the PK model building cohort two different analytical techniques were used: immunoassay and liquid chromatography-tandem mass spectrometry. However, to solve this issue, this difference was built into the residual error model. We chose not to exclude the immunoassay concentrations as they were included in the original model. Furthermore, the relatively large proportion of Caucasian patients in our center is a limitation as this may not reflect pediatric transplant populations worldwide.

\section{Conclusions}

In a prospective study, a validated tacrolimus dosing algorithm was poorly predictive of the individual tacrolimus starting dose following renal transplantation in children. On day 3 , a total of only $31 \%$ of patients was within the target tacrolimus pre-dose concentration range. The dosing algorithm was subsequently improved using data of children included in this trial and was able to adequately describe the tacrolimus pharmacokinetics the first 6 weeks following kidney transplantation. The weight-normalized starting dose of tacrolimus should be higher in patients with a lower bodyweight and in those who are CYP3A5 expressers. However, as the negative result of this trial demonstrates, a prospective study is needed to demonstrate the accuracy of this improved model.
Acknowledgements The authors are grateful to the statistician B. van der Holt for his valuable contribution to the design of this clinical study.

\section{Compliance with Ethical Standards}

Funding No funding was received for the conduct of this study or preparation of this article.

Conflict of interest Brenda C. M. de Winter has received Grant support from Astellas Pharma. Dennis A. Hesselink has received lecture and consulting fees from Astellas Pharma and Chiesi Farmaceutici Spa, as well as Grant support (paid to his institution) from Astellas Pharma, Chiesi Farmaceutici Spa, and Bristol Myers-Squibb. Teun van Gelder has received lecture and consulting fees from Astellas Pharma, Vitaeris, Aurinia Pharma, Roche Diagnostics, and Chiesi Farmaceutici $\mathrm{Spa}$, as well as Grant support (paid to his institution) from Astellas Pharma and Chiesi Farmaceutici Spa. Elisabeth A. M. Cornelissen, Louise M. Andrews, Michiel F. Schreuder, Roger J. M. Brüggemann, and Karlien Cransberg have no conflicts of interest that are directly relevant to the content of this article.

Open Access This article is distributed under the terms of the Creative Commons Attribution-NonCommercial 4.0 International License (http://creativecommons.org/licenses/by-nc/4.0/), which permits any noncommercial use, distribution, and reproduction in any medium, provided you give appropriate credit to the original author(s) and the source, provide a link to the Creative Commons license, and indicate if changes were made.

\section{References}

1. Hariharan S, Johnson CP, Bresnahan BA, Taranto SE, McIntosh MJ, Stablein D. Improved graft survival after renal transplantation in the United States, 1988 to 1996. N Engl J Med. 2000;342(9):605-12.

2. Kidney Disease: Improving Global Outcomes Transplant Work G. KDIGO clinical practice guideline for the care of kidney transplant recipients. Am J Transplant. 2009;9(Suppl. 3):S1-155.

3. Meier-Kriesche HU, Li S, Gruessner RW, Fung JJ, Bustami RT, Barr ML, et al. Immunosuppression: evolution in practice and trends, 1994-2004. Am J Transplant. 2006;6(5 Pt 2):1111-31.

4. Brunet M, van Gelder T, Asberg A, Haufroid V, Hesselink DA, Langman L, et al. Therapeutic drug monitoring of tacrolimuspersonalized therapy: second consensus report. Ther Drug Monit. 2019;41(3):261-307.

5. Mayer TU, Marx A. Five molecules we would take to a remote island. Chem Biol. 2010;17(6):556-60.

6. Burckart GJ, Liu XI. Pharmacogenetics in transplant patients: can it predict pharmacokinetics and pharmacodynamics? Ther Drug Monit. 2006;28(1):23-30.

7. Hesselink DA, Bouamar R, Elens L, van Schaik RH, van Gelder $\mathrm{T}$. The role of pharmacogenetics in the disposition of and response to tacrolimus in solid organ transplantation. Clin Pharmacokinet. 2014;53(2):123-39.

8. Hesselink DA, van Schaik RH, van Agteren M, de Fijter JW, Hartmann A, Zeier M, et al. CYP3A5 genotype is not associated with a higher risk of acute rejection in tacrolimus-treated renal transplant recipients. Pharmacogenet Genom. 2008;18(4):339-48.

9. Naesens M, Kuypers DR, Sarwal M. Calcineurin inhibitor nephrotoxicity. Clin J Am Soc Nephrol. 2009;4(2):481-508. 
10. Hesselink DA, Hoorn EJ. Improving long-term outcomes of kidney transplantation: the pressure is on. Neth $\mathrm{J}$ Med. 2014;72(5):248-50.

11. Lamb KE, Lodhi S, Meier-Kriesche HU. Long-term renal allograft survival in the United States: a critical reappraisal. Am J Transplant. 2011;11(3):450-62.

12. Passey C, Birnbaum AK, Brundage RC, Oetting WS, Israni AK, Jacobson PA. Dosing equation for tacrolimus using genetic variants and clinical factors. Br J Clin Pharmacol. 2011;72(6):948-57.

13. Staatz CE, Tett SE. Clinical pharmacokinetics and pharmacodynamics of tacrolimus in solid organ transplantation. Clin Pharmacokinet. 2004;43(10):623-53.

14. Grenda R, Watson A, Trompeter R, Tonshoff B, Jaray J, Fitzpatrick $\mathrm{M}$, et al. A randomized trial to assess the impact of early steroid withdrawal on growth in pediatric renal transplantation: the TWIST study. Am J Transplant. 2010;10(4):828-36.

15. de Wildt SN, van Schaik RH, Soldin OP, Soldin SJ, Brojeni PY, van der Heiden IP, et al. The interactions of age, genetics, and disease severity on tacrolimus dosing requirements after pediatric kidney and liver transplantation. Eur J Clin Pharmacol. 2011;67(12):1231-41.

16. Naesens M, Salvatierra O, Li L, Kambham N, Concepcion W, Sarwal M. Maturation of dose-corrected tacrolimus predose trough levels in pediatric kidney allograft recipients. Transplantation. 2008;85(8):1139-45.

17. Andrews LM, Hesselink DA, Van Gelder T, Koch BC, Cornelissen EAM, Bruggemann RJM, et al. A population pharmacokinetic model to predict the individual starting dose of tacrolimus following pediatric renal transplantation. Clin Pharmacokinet. 2018;57(4):475-89.

18. Kausman JY, Patel B, Marks SD. Standard dosing of tacrolimus leads to overexposure in pediatric renal transplantation recipients. Pediatr Transplant. 2008;12(3):329-35.

19. Zhao W, Elie V, Roussey G, Brochard K, Niaudet P, Leroy V, et al. Population pharmacokinetics and pharmacogenetics of tacrolimus in de novo pediatric kidney transplant recipients. Clin Pharmacol Ther. 2009;86(6):609-18.

20. van Gelder T. Drug interactions with tacrolimus. Drug Saf. 2002;25(10):707-12.

21. Prytula A, van Gelder T. Clinical aspects of tacrolimus use in paediatric renal transplant recipients. Pediatr Nephrol. 2019;34(1):31-43.

22. Oetting WS, Schladt DP, Guan W, Miller MB, Remmel RP, Dorr $\mathrm{C}$, et al. Genomewide association study of tacrolimus concentrations in African American kidney transplant recipients identifies multiple CYP3A5 alleles. Am J Transplant. 2016;16(2):574-82.

23. Tang JT, Andrews LM, van Gelder T, Shi YY, van Schaik $\mathrm{RH}$, Wang LL, et al. Pharmacogenetic aspects of the use of tacrolimus in renal transplantation: recent developments and ethnic considerations. Expert Opin Drug Metabol Toxicol. 2016;12(5):555-65.

24. Staatz CE, Willis C, Taylor PJ, Tett SE. Population pharmacokinetics of tacrolimus in adult kidney transplant recipients. Clin Pharmacol Ther. 2002;72(6):660-9.

25. Schijvens AM, van Hesteren FHS, Cornelissen EAM, BootsmaRobroeks C, Bruggemann RJM, Burger DM, et al. The potential impact of hematocrit correction on evaluation of tacrolimus target exposure in pediatric kidney transplant patients. Pediatr Nephrol. 2019;34(3):507-15.

26. Andrews LM, Riva N, de Winter BC, Hesselink DA, de Wildt $\mathrm{SN}$, Cransberg K, et al. Dosing algorithms for initiation of immunosuppressive drugs in solid organ transplant recipients. Expert Opin Drug Metab Toxicol. 2015;11(6):921-36.

27. Simon R. Optimal two-stage designs for phase II clinical trials. Control Clin Trials. 1989;10(1):1-10.
28. Schwartz GJ, Munoz A, Schneider MF, Mak RH, Kaskel F, Warady BA, et al. New equations to estimate GFR in children with CKD. J Am Soc Nephrol. 2009;20(3):629-37.

29. Jonsson EN, Karlsson MO. Automated covariate model building within NONMEM. Pharm Res. 1998;15(9):1463-8.

30. Andrews LM, De Winter BC, Van Gelder T, Hesselink DA. Consideration of the ethnic prevalence of genotypes in the clinical use of tacrolimus. Pharmacogenomics. 2016;17(16):1737-40.

31. Andrews LM, Hesselink DA, van Schaik RHN, van Gelder T, de Fijter JW, Lloberas N, et al. A population pharmacokinetic model to predict the individual starting dose of tacrolimus in adult renal transplant recipients. Br J Clin Pharmacol. 2019;85(3):601-15.

32. Birdwell KA, Decker B, Barbarino JM, Peterson JF, Stein CM, Sadee W, et al. Clinical Pharmacogenetics Implementation Consortium (CPIC) guidelines for CYP3A5 genotype and tacrolimus dosing. Clin Pharmacol Ther. 2015;98(1):19-24.

33. Macphee IA, Fredericks S, Tai T, Syrris P, Carter ND, Johnston A, et al. Tacrolimus pharmacogenetics: polymorphisms associated with expression of cytochrome p4503A5 and P-glycoprotein correlate with dose requirement. Transplantation. 2002;74(11):1486-9.

34. Picard N, Bergan S, Marquet P, van Gelder T, Wallemacq P, Hesselink DA, et al. Pharmacogenetic biomarkers predictive of the pharmacokinetics and pharmacodynamics of immunosuppressive drugs. Ther Drug Monit. 2016;38(Suppl. 1):S57-69.

35. Prytula AA, Cransberg K, Bouts AH, van Schaik RH, de Jong $\mathrm{H}$, de Wildt SN, et al. The effect of weight and CYP3A5 genotype on the population pharmacokinetics of tacrolimus in stable paediatric renal transplant recipients. Clin Pharmacokinet. 2016;55(9):1129-43.

36. Andreu F, Colom H, Elens L, van Gelder T, van Schaik RH, Hesselink DA, et al. A new CYP3A5*3 and CYP3A4*22 cluster influencing tacrolimus target concentrations: a population approach. Clin Pharmacokinet. 2017;56(8):963-75.

37. Min S, Papaz T, Lafreniere-Roula M, Nalli N, Grasemann H, Schwartz SM, et al. A randomized clinical trial of age and genotype-guided tacrolimus dosing after pediatric solid organ transplantation. Pediatr Transplant. 2018;22(7):e13285.

38. Shuker N, Bouamar R, van Schaik RH, Clahsen-van Groningen MC, Damman J, Baan CC, et al. A randomized controlled trial comparing the efficacy of CYP3A5 genotype-based with bodyweight-based tacrolimus dosing after living donor kidney transplantation. Am J Transplant. 2016;16(7):2085-96.

39. Thervet E, Loriot MA, Barbier S, Buchler M, Ficheux M, Choukroun $\mathrm{G}$, et al. Optimization of initial tacrolimus dose using pharmacogenetic testing. Clin Pharmacol Ther. 2010;87(6):721-6.

40. Press RR, Ploeger BA, Hartigh JD, Straaten TVD, Pelt JV, Danhof M, et al. Explaining variability in tacrolimus pharmacokinetics to optimize early exposure in adult kidney transplant recipients. Ther Drug Monit. 2009;31(2):187-97.

41. Venkataramanan R, Swaminathan A, Prasad T, Jain A, Zuckerman S, Warty V, et al. Clinical pharmacokinetics of tacrolimus. Clin Pharmacokinet. 1995;29(6):404-30.

42. Asberg A, Midtvedt K, van Guilder M, Storset E, Bremer S, Bergan $\mathrm{S}$, et al. Inclusion of CYP3A5 genotyping in a nonparametric population model improves dosing of tacrolimus early after transplantation. Transpl Int. 2013;26(12):1198-207.

43. Størset E, Holford N, Hennig S, Bergmann TK, Bergan S, Bremer $\mathrm{S}$, et al. Improved prediction of tacrolimus concentrations early after kidney transplantation using theorybased pharmacokinetic modelling. Br J Clin Pharmacol. 2014;78(3):509-23. 
44. Storset E, Holford N, Midtvedt K, Bremer S, Bergan S, Asberg A. Importance of hematocrit for a tacrolimus target concentration strategy. Eur J Clin Pharmacol. 2014;70(1):65-77.

45. Woillard JB, de Winter BC, Kamar N, Marquet P, Rostaing L, Rousseau A. Population pharmacokinetic model and Bayesian estimator for two tacrolimus formulations: twice daily Prograf and once daily Advagraf. Br J Clin Pharmacol. 2011;71(3):391-402.

46. Fukatsu S, Yano I, Igarashi T, Hashida T, Takayanagi K, Saito $\mathrm{H}$, et al. Population pharmacokinetics of tacrolimus in adult recipients receiving living-donor liver transplantation. Eur $\mathbf{J}$ Clin Pharmacol. 2001;57(6-7):479-84.

47. Jacobson P, Ng J, Ratanatharathorn V, Uberti J, Brundage RC. Factors affecting the pharmacokinetics of tacrolimus (FK506) in hematopoietic cell transplant (HCT) patients. Bone Marrow Transplant. 2001;28(8):753-8.
48. Gruber SA, Hewitt JM, Sorenson AL, Barber DL, Bowers L, Rynders G, et al. Pharmacokinetics of FK506 after intravenous and oral administration in patients awaiting renal transplantation. J Clin Pharmacol. 1994;34(8):859-64.

49. Sam WJ, Tham LS, Holmes MJ, Aw M, Quak SH, Lee KH, et al. Population pharmacokinetics of tacrolimus in whole blood and plasma in Asian liver transplant patients. Clin Pharmacokinet. 2006;45(1):59-75.

50. Staatz CE, Willis C, Taylor PJ, Lynch SV, Tett SE. Toward better outcomes with tacrolimus therapy: population pharmacokinetics and individualized dosage prediction in adult liver transplantation. Liver Transplant. 2003;9(2):130-7.

51. Sheiner LB, Beal S, Rosenberg B, Marathe VV. Forecasting individual pharmacokinetics. Clin Pharmacol Ther. 1979;26(3):294-305. 